\title{
SIMULASI DAN ANALISIS PERFORMANSI DARI PROTOKOL ROUTING BERBASIS POSISI GPRS DAN GyTAR UNTUK VEHICLE COMMUNICATION PADA VEHICULAR AD HOC NETWORK (VANET)
}

\author{
Irma Nurlita Dewi ${ }^{1}$, Rendy Munadi ${ }^{2}$, Leanna Vidya Y. ${ }^{3}$ \\ 1,2,3Fakultas Teknik Elektro, Universitas Telkom
}

1irmanurlitadewi@gmail.com, ${ }^{2}$ rendymunadi@telkomuniversity.ac.id, ${ }^{3}$ leanna@ @elkomuniversity.ac.id

\begin{abstract}
Abstrak
Vehicular Ad hoc Network (VANET) merupakan konsep subset dari Mobile Ad hoc Networks (MANET) sebagai teknologi yang memungkinkan komunikasi Inter Vehicle Communication (IVC) dan Roadside-toVehicle (RVC).VANET dikarakteristikkan dengan membangun jaringan ad hoc yang dibentuk dari nodenode berupa kendaraan bermobilitas tinggi yang dibatasi dengan aturan lalu lintas sehingga pergerakannya disesuaikan dengan pola tertentu, tidak seperti MANET yang pergerakannya bisa random tanpa ada batasan. Dengan demikian, protokol routing konvensional berbasis topologi pada MANET dinilai tidak cocok untuk VANET. Protokol routing berbasis posisi sepeti GPSR dan GyTAR dinilai cocok untuk VANET. Hal ini tak lain karena aspek dinamika topologi pada VANET yang dapat berdampak nyata pada analisis protokol routing. Dari hasil simulasi diperoleh bahwa GyTAR unggul pada skenario lingkungan perkotaan dilihat dari seluruh parameter end-to-end delay, packet delivery ratio, packet loss dan normalized routing overhead yang lebih baik dari GPSR dengan rata-rata nilai masing-masing, yakni $2,294 \mathrm{~ms}, 0,958$, 4,19\%, dan 0,482. Sementara pada skenario lingkungan jalan tol GPSR lebih unggul dibandingkan GyTAR dengan rata-rata nilai end-to-end delay, packet delivery ratio, dan packet loss sebesar $2,639 \mathrm{~ms}, 0,920$, dan 7,923\%; namun dengan perolehan NRO yang lebih kecil oleh GyTAR, yakni sebesar 1,725.
\end{abstract}

Kata Kunci: VANET, MANET , GPSR, GyTAR, IVC, SUMO

Abstract

Vehicular Ad hoc Network (VANET) is a subset concept of Mobile Ad hoc Networks (MANET) that provides Inter Vehicle Communications (IVC) and or Roadside-to-Vehicle Communication (RVC). VANET is characterized by the ad hoc network infrastructure from highly dynamic vehicular nodes that move on predefined roads and traffic sign, unlike MANET that can move around randomly with no boundaries. Compare with MANET, VANET has higher node mobility and more complex pattern since the speed and behavior of driver are varied. Thus, the conventional topology-based routing protocols are no longer efficient for VANET. Position-based routing protocols like GPSR and GyTAR are more suitable for VANET. This is because these routing protocols can affect significantly to the highly dynamic nature of vehicular nodes. From the simulation result obtained that GyTAR outperforms GPSR in urban scenario for all performance metrics: end-to-end delay, packet delivery ratio, packet loss and normalized routing overhead better than GPSR, which its value respectively are $22.294 \mathrm{~ms}, \mathbf{0 . 9 5 8}, 4.19 \%$, dan 0.482 . While in highway scneario, GPSR outperforms GyTAR with average value of end-to-end delay, packet delivery ratio, and packet loss respectively are $2.639 \mathrm{~ms}, 0.920$, and $7.923 \%$; but posing less NRO of 1.725 by GyTAR.

Keywords: VANET, MANET, GPRS, GyTAR, IVC, SUMO

\section{Pendahuluan}

Sebuah konsep baru telah berkembang yang memungkinkan komunikasi antar kendaraan (inter vehicle) dan komunikasi antara kendaraan dengan infrastruktur di sekitar jalan (vehicle to roadside). Konsep jaringan wireless yang merupakan subset dari Mobile Ad hoc Network (MANET) ini dikenal sebagai Vehicular Ad hoc Network (VANET). Komunikasi yang berlangsung pada VANET ini nantinya dapat digunakan untuk menyediakan aplikasi-aplikasi transportasi untuk keperluan keamanan, hiburan, hingga aplikasi untuk kenyamanan pengendara. VANET membangun ad hoc network-nya di antara kendaraan-kendaraan dengan dinamika pergerakan node yang tinggi, tentunya memerlukan implementasi protokol routing yang sesuai dengan karakteristiknya. Walaupun merupakan subset dari MANET, protokol-protokol routing konvensional yang sebelumnya diimplementasikan pada MANET dinilai kurang adaptif jika diimplementasikan secara murni pada VANET. Hal ini karena VANET memiliki beberapa karakteristik yang amat membedakan dirinya dari MANET. Mobilitas node yang lebih tinggi dengan dibatasi oleh aturan dan jalur lalu lintas serta 
dilibatkannya kecepatan, perilaku pengendara, dan tersedianya alternatif rute-rute perjalanan menjadi beberapa poin pembeda dari MANET $[2,5,9]$.

Tujuan dari penelitian ini adalah menyimulasikan dan menganalisis perbandingan kinerja dua protokol routing berbasis posisi, yakni Greedy Perimeter Stateless Routing (GPSR) dan Greedy Traffic Aware Routing (GyTAR) untuk komunikasi antar kendaraan pada VANET di atas lingkungan perkotaan dan jalan tol, dengan metrik performasi berupa end-to-end delay, packet delivery ratio, packet loss, dan normalized routing overhead.

\section{Konsep Vehicular Ad Hoc Network}

\subsection{Vehicular Ad Hoc Network}

Vehicular Ad hoc Network (VANET) merupakan subset dari Mobile Ad hoc Network (MANET) yang membangun ad hoc network di antara kendaraan-kendaraan. Komunikasi wireless ini meliputi komunikasi inter-vehicle communication (IVC), vehicle to roadside (V2R), atau roadside to roadside (R2R). VANET ini kelak akan sangat berperan pada perkembangan teknologi Intelligent Transportation System (ITS) dalam menyediakan aplikasi keamanan dan kenyamanan bagi para pengendara jalan.

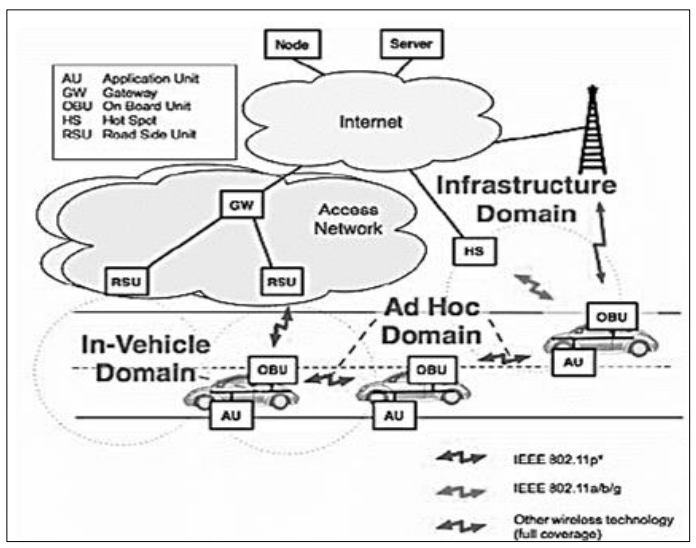

Gambar 1. Arsitektur Sistem VANET [2]

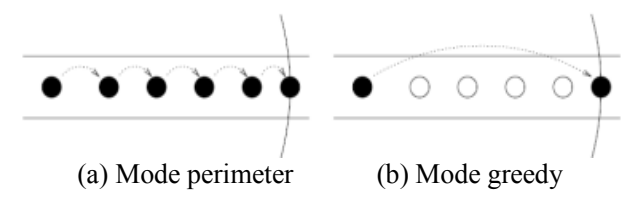

Gambar 2. Mode pada GPSR

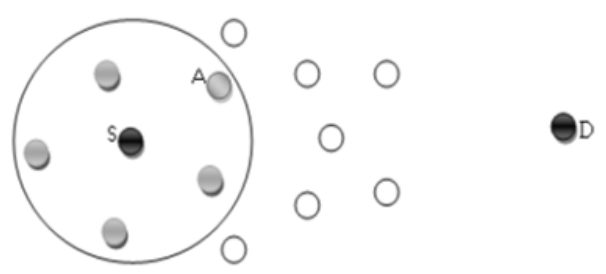

Gambar 3. Pemilihan persimpangan pada GyTAR [8]

\subsection{Karakteristik VANET}

VANET memiliki beberapa karakteristik khusus yang membedakannya dari jaringan ad hoc lainnya. Karakteristik tersebut antara lain $[5,11]$ :

\section{a. Topologi yang sangat dinamis}

Jika diasumsikan dua kendaraan bergerak berjauhan dengan kecepatan masing-masing $60 \mathrm{mph}$ $(25 \mathrm{~m} / \mathrm{s})$ dengan range transmisi $250 \mathrm{~m}$, maka link di antara kedua kendaraan ini akan berakhir dalam 5 detik $(250 \mathrm{~m}$ atau $50 \mathrm{~m} / \mathrm{s})$. Hal ini mengindikasikan sebuah topologi yang sangat dinamis.

\section{b. Putusnya koneksi jaringan secara berkala}

Pada jaringan dinamis sebagaimana dijelaskan di atas, putusnya koneksi yang disebabkan perubahan informasi (posisi, arah, dll) dari kendaraan yang berkomunikasi dapat terjadi secara berkala khususnya pada jaringan di jalan yang lengang seperti jalan tol.

\section{c. Model mobilitas dan prediksi}

Pola mobilitas node masing-masing kendaraan bergantung pada lingkungan lalu lintas (baik itu perkotaan atau jalan tol), struktur jalan, kecepatan kendaraan, perilaku pengendara, dan lain sebagainya.

\section{d. Hard Delay Constraints}

Aspek keamanan dari aplikasi VANET (seperti kecelakaan, masalah rem, dan lain-lain) harus menjamin kecepatan pengiriman pesan ke node-node yang relevan. Dengan demikian, pemecahan isu hard delay contraints menjadi lebih penting dari high data rate pada VANET.

\section{e. Daya baterai dan kapasitas storage}

Berbeda dengan MANET, pada VANET, kendaraan modern memiliki daya baterai dan kapasitas storage yang tak terbatas sehingga sangat membantu dalam proses komunikasi dan routing.

\section{f. Interaksi dengan sensor onboard}

Posisi terkini dan pergerakan node dapat dengan mudah dikirim dengan sensor onboard seperti GPS. Ini akan membantu komunikasi yang lebih efektif dan begitu pula halnya dalam keputusan routing.

\subsection{Arsitektur VANET}

Sebuah arsitektur VANET terdiri dari domaindomain berbeda dan komponen-komponen individual sebagaimana tertera pada Gambar 1 yang menunjukkan tiga domain berbeda dalam kendaraan (vehicle), ad hoc, dan infrastruktur, termasuk di dalamnya komponen individual (application unit, onboard unit, dan road-side unit). 


\section{a. In-Vehicle Domain}

Dalam sebuah kendaraan, terdiri sebuah onboard unit (OBU) dan satu atau lebih applications units (AU). AU mengeksekusi seperangkat aplikasi yang memanfaatkan kemampuan komunikasi OBU.

\section{b. Ad hoc Domain}

Sebuah domain ad hoc terdiri dari kendaraankendaraan yang dilengkapi dengan OBU dan roadside units (RSUs) yang tanpa koordinasi terpusat membentuk VANET.

\section{c. Infrastructure Domain}

Sebuah infrastruktur terdiri dari RSU dan Wireless Hotspots (HT) yang dapat diakses kendaraan sebagai aplikasi keamanan ataupun nonkeamanan. Ketika RSU digunakan untuk mengakses internet, biasanya diatur oleh road administrator atau public authorities lain.

\subsection{Inter Vehicle Communication (IVC)}

Meng-install infrastruktur permanen di jalan raya seperti access points, base stations dapat menelan banyak biaya, maka komunikasi antar kendaraan (IVC) akan dibutuhkan untuk meningkatkan efektivitas cakupan jaringan kendaraan. Komunikasi IVC murni merupakan jaringan ad hoc dan banyak digunakan untuk aplikasi keamanan seperti peringatan keselamatan, informasi lalu lintas, peringatan penghalang jalan, dan lain-lain. Pada komunikasi ini, masing-masing kendaraan telah dilengkapi dengan on board unit seperti GPS (Global Positioning System). Kendaraan akan mendeteksi sendiri pesan lalu lintasnya dan berkomunikasi dengan kendaraan tetangga dengan mem-broadcast beacon atau pesan HELLO secara periodik [6].

\subsection{Position-Based Routing Protocol}

Position-Based Routing (PBR) menyajikan komunikasi multihop untuk wireless ad hoc network, di mana node-node saling berbagi informasi posisi untuk memilih forwarding hop berikutnya. Pada routing yang demikian, setiap node dianggap mengetahui posisi geografisnya masing-masing dengan bantuan GPS dan menjaga tabel lokasinya dengan ID dan informasi geografis dari node-node yang lain. Jika sebuah node ingin mengirim paket, sebuah location service dapat digunakan untuk membantu menentukan posisi dari tujuan. Paket dikirim ke tetangga satu hop-nya yang terletak paling dekat dengan tujuan. Untuk memungkinkan hal demikian, setiap node harus secara kontinu mengirimkan paket beacon lengkap dengan posisi mereka dan ID node-nya. Hal ini penting untuk membangun tabel tetangga satu-hop [7].
Demikian pula halnya pada kendaraan. Pada VANET, masing-masing kendaraan perlu tahu posisinya sendiri dan posisi kendaraan lainnya karena position-based routing protocol membutuhkan informasi mengenai lokasi fisik dari kendaraan yang tersedia untuk berpartisipasi dan ini diperoleh secara periodik dari beacon dari tetangga langsung atau dari perangkat location service.

\subsection{Greedy Perimeter Stateless Routing (GPSR)}

Pada Greedy Perimeter Stateless Routing (GPSR), sebuah node menemukan lokasi tetangganya menggunakan perangkat HELLO messages dan posisi tujuan dengan bantuan location services, sebagaimana yang tertera pada Gambar 2 GPSR membutuhkan tiap node-nya yang berada dalam jaringan untuk mampu menemukan posisi terkininya menggunakan GPS receiver yang menyediakan informasi terbaru mengenai kecepatan, waktu, dan arah kendaraan. Dengan informasi-informasi ini, sebuah node dapat mem-forward paket ke tetangganya yang terdekat dari tujuan. Mode operasi seperti ini dikenal sebagai Greedy Forwarding sebagaimana yang tertera pada [3] dan [8].

GPSR menerapkan greedy forwarding secara murni dan void handling sebagai strategi recoverynya, atau dikenal dengan perimeter routing ketika local optima terjadi. Node yang memulai mode perimeter menyimpan posisi dirinya sendiri pada header paket. Jika sebuah node menerima paket yang demikian dan memiliki sebuah node tetangga yang lebih dekat ke tujuan dari pada posisi yang terdapat dalam header, maka mode akan kembali lagi menjadi mode greedy routing.

\subsection{Greedy Traffic Aware Routing (GyTAR)}

GyTAR merupakan protokol routing berbasis posisi intersection dalam rute pengiriman paket. GyTAR merepresentasikan skema routing anchorbased dengan traffic aware, sebagaimana yang tertera pada Gambar 3 GyTAR terdiri dari dua modul yang juga menjadi metode transmisi paket, yakni $[3,8]$ :

\section{a. Junction Selecti}

Pada GyTAR, persimpangan berbeda yang harus dilalui paket untuk menuju node tujuan dipilih satu per satu secara dinamis, mempertimbangkan variasi trafik kendaraan dan jarak ke tujuan. Ketika memilih persimpangan selanjutnya, sebuah node akan mencari posisi tetangga di persimpangan lain menggunakan peta. Sebuah nilai diberikan pada tiaptiap persimpangan untuk mempertimbangkan kepadatan trafik dan jarak curvemetric ke tujuan. Persimpangan tujuan terbaik (persimpangan dengan nilai terbesar) adalah persimpangan yang secara geografis paling dekat dengan kendaraan tujuan dan yang memiliki trafik kendaraan tertinggi. Pada Gambar 4 digambarkan bagaimana persimpangan 
selanjutnya dipilih pada sebuah jalan. Suatu ketika kendaraan menerima paket, ia akan menghitung nilai dari masing-masing tetangga persimpangannya. Dengan memperhitungkan jarak curvemetric ke tujuan dan kepadatan trafik, persimpangan J2 memiliki nilai yang lebih besar. Maka itu, persimpangan ini dipilih sebagai anchor selanjutnya.

\section{b. Strategi recovery}

Suatu ketika mekanisme GyTAR membawa pada kondisinya lokal optimum (ketika forwarding vehicle-lah yang lebih dekat dengan persimpangan), maka strategi recovery diterapkan. Strategi recovery ini dikenal sebagai "carry and forward", yakni node pembawa paket akan membawa paket sampai persimpangan berikutnya atau sampai ada node kendaraan lain yang lebih dekat dengan node tujuan masuk ke dalam radius transmisinya.

\subsection{Simulasi VANET}

Simulasi VANET memerlukan dua tipe komponen simulasi, yakni jaringan dan mobilitas. Pada banyak kasus, simulator jaringan dan simulator

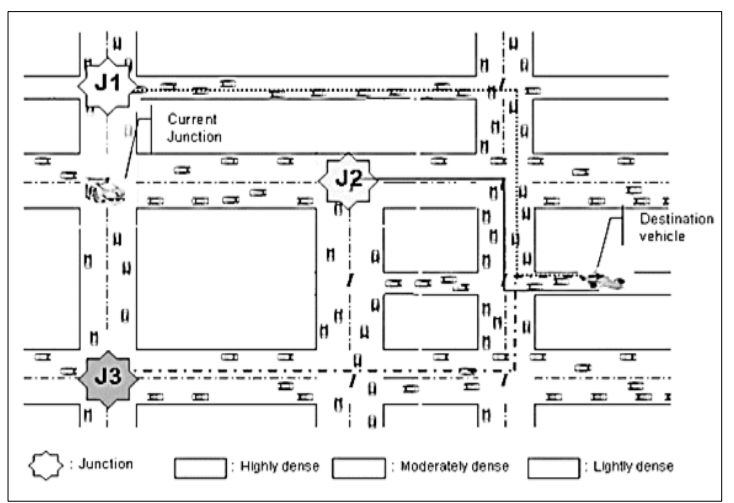

Gambar 4. Pemilihan Persimpangan pada GyTAR [8]

Tabel 1. Parameter Umum Simulasi

\begin{tabular}{|l|l|}
\hline \multicolumn{1}{|c|}{ Parameter } & \multicolumn{1}{c|}{ Nilai } \\
\hline Area Simulasi & $12,5 \mathrm{~km} \times 9,5 \mathrm{~km}$ (kota) dan $15 \mathrm{~km} \times$ \\
& $12,5 \mathrm{~km}$ (jalan tol) \\
\hline Jumlah Kendaraan & 100 \\
\hline Jumlah Komunikasi & $10,20,30$ \\
\hline Packet Type & CBR, FTP, RTP \\
\hline Rata-rata Kecepatan Kendaraan & $\begin{array}{l}30-50 \mathrm{~km} / \mathrm{jam}(\mathrm{kota}) \text { dan } 60-100 \\
\mathrm{~km} / \mathrm{jam} \text { (jalan tol) }\end{array}$ \\
\hline Transmission Range & $250 \mathrm{~m}$ \\
\hline Hello Interval & $0,5 \mathrm{~s}$ \\
\hline & $802.11 \mathrm{DCF}$ \\
\hline & $300 \mathrm{~s}$ \\
\hline
\end{tabular}

Tabel 2. Spesifikasi Layanan

\begin{tabular}{|c|c|}
\hline Layanan & Spesifikasi \\
\hline Data & $\begin{array}{l}\text { - File Size: } 1024 \text { bytes } \\
\text { - Data Rate: } 64 \mathrm{kbps} \\
\text { Type of Service: File transfer }\end{array}$ \\
\hline Suara & $\begin{array}{l}\text { - File Size: } 206 \text { bytes } \\
\text { - Data Rate: } 64 \mathrm{kbps} \\
\text { Type of Service: Voice over IP (VolP) }\end{array}$ \\
\hline Video & $\begin{array}{l}\text { - File Size: } 500 \text { bytes } \\
\text { - Data Rate: } 128 \mathrm{kbps} \\
\\
\text { Type of Service: Video Streaming }\end{array}$ \\
\hline
\end{tabular}

mobilitas dibuat terpisah. Software simulator untuk VANET ini dikelompokkan menjadi tiga kategori: (a) Mobility Simulator; (b) Network Simulator; dan (c) Software yang mengintegrasikan keduanya atau yang mampu mensimulasikan baik simulasi mobilitas maupun simulasi jaringan.

Pada penelitian ini, konfigurasi peta dan mobilitas dilakukan menggunakan VanSimFM (VANET Simulation Framework Modeller) yang bekerja di atas simulator micro-traffic SUMO (Simulation of Urban Mobility). Keluarannya berupa Tcl script kemudian di-generate bersama protokol routing menggunakan network simulator NS-2 untuk dianalisis masing-masing performansinya.

\section{Perancangan Sistem}

Pada penelitian ini menggunakan dua skenario lingkungan dalam menganalisis protokol routing GPSR dan GyTAR, yakni lingkungan perkotaan dan jalan tol. Adapun parameter simulasi yang digunakan secara umum tersaji pada Tabel 1. Sedangkan untuk trafik yang dikirimkan dari node sumber ke node tujuan pada simulasi ini meliputi data, suara dan video. Dengan spesifikasi dari tiap layanan tertera pada Tabel 2.

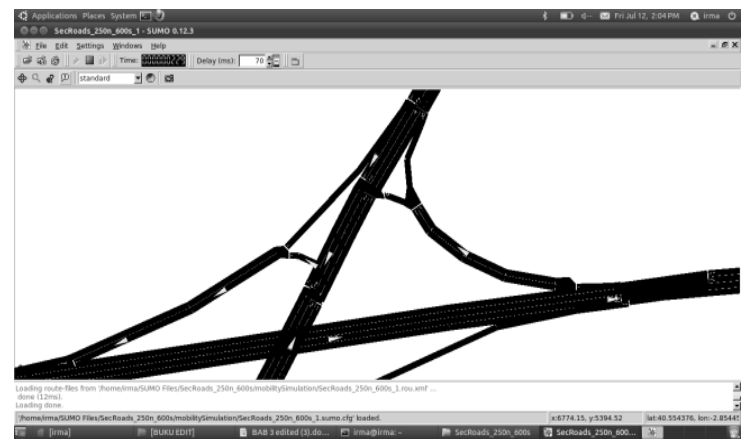

Gambar 5. Tampilan Mobilitas Peta Perkotaan

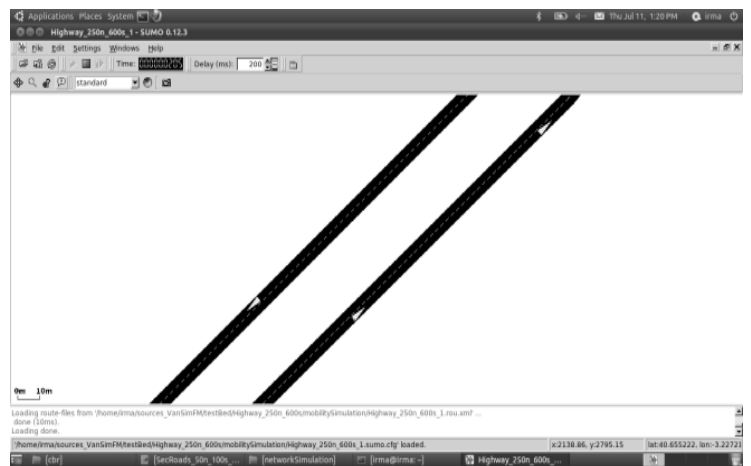

Gambar 6. Tampilan Mobilitas Peta Jalan Tol

Tabel 3. End-to-end Delay GPSR dan GyTAR di Perkotaan

\begin{tabular}{|c|c|c|c|c|c|}
\hline \multirow{7}{*}{$\begin{array}{l}\text { End-to-end } \\
\text { Delay (ms) }\end{array}$} & \multicolumn{2}{|c|}{ Komunikasi Node } & 10 & 20 & 30 \\
\hline & \multirow{3}{*}{ GPSR } & Data & 2,5012 & 2,6620 & 2.8059 \\
\hline & & Suara & 2,3831 & 2,5259 & 2,7232 \\
\hline & & Video & 2,6162 & 2,7016 & 2,8231 \\
\hline & \multirow{3}{*}{ GyTAR } & Data & 2,2432 & 2,2857 & 2,3538 \\
\hline & & Suara & 2,1372 & 2,1412 & 2,2774 \\
\hline & & Video & 2,3513 & 2,3985 & 2,5479 \\
\hline
\end{tabular}




\subsection{Skenario Lingkungan}

Adapun beberapa skenario yang dilakukan dalam penelitian ini, antara lain:

\section{a. Lingkungan Perkotaan}

Pada skenario lingkungan perkotaan yang tertera pada Gambar 5, digunakan peta sektoral dari wilayah kota Banjar, Jawa Barat dengan luas 12,5 km $\times 9,5 \mathrm{~km}$ dengan jumlah node sebanyak 100 node kendaraan untuk waktu simulasi selama 300 detik. Adapun arah dan kecepatan pergerakan masingmasing random dengan range kecepatan berkisar antara 30 - $50 \mathrm{~km}$ per jam dan jumlah komunikasi yang dibangun berturut-turut sebanyak 10, 20, dan 30 koneksi. Pada skenario ini diterapkan mekanisme lampu lalu lintas sebagaimana kondisi nyata di perkotaan.

\section{b. Lingkungan Jalan Tol}

Pada skenario jalan tol, sebagaimana yang tertera pada Gambar 6, digunakan peta sektoral jalan tol Cipularang, Jawa Barat, Indonesia, pada jalur Sadang - Cikamuning, dengan luas $15 \mathrm{~km} \times 12,5 \mathrm{~km}$. Peta jalan tol ini terdiri dari dua jalur searah dengan kondisi jalan lurus tanpa ada persimpangan. Jumlah kendaraan yang bergerak di atas peta ini yakni sebanyak 100 node kendaraan dengan waktu simulasi 300 detik.

Adapun node-node tiap kendaraan bergerak dengan arah dan kecepatan pergerakan yang random dengan kisaran kecepatan $60-100 \mathrm{~km}$ per jam. Jumlah koneksi yang terjadi berturut-turut sebanyak 10, 20, dan 30 komunikasi.

\section{Hasil Simulasi dan Analisis}

\subsection{Analisis Skenario Lingkungan Perkotaan}

\subsubsection{Analisis End-to-End Delay}

Berdasarkan skenario lingkungan perkotaan dengan jumlah node kendaraan sebanyak 100 dan jumlah koneksi yang terjadi masing-masing sebanyak 10, 20, 30, 40, dan 50 komunikasi, didapatkan nilai end-to-end delay untuk protokol routing GPSR dan GyTAR dapat terlihat di Tabel 3.

Dari Tabel 3 terlihat bahwa pada kedua protokol routing baik GPSR maupun GyTAR, terjadi peningkatan nilai average end-to-end delay sebesar kisaran 0,004 ms sampai 0,1973 ms seiring dengan bertambahnya jumlah komunikasi antar node kendaraan yang terjadi. Perubahan nilai secara gradual yang relatif tipis menunjukkan bahwa kedua algoritma routing cukup adaptif pada vehicular network yang memiliki mobilitas dan konektivitas yang tinggi.

Kedua protokol routing menunjukkan perbedaan yang konsisten pada nilai end-to-end delay untuk layanan data, suara, dan video dengan GyTAR yang terus mengungguli GPSR. Adapun nilai end-toend delay pada komunikasi data menggunakan algoritma routing GPSR untuk jumlah koneksi masing-masing 10,20 , dan 30 adalah $2,5012 \mathrm{~ms}$, 2,6620 ms, dan 2,8059 ms. Sedangkan komunikasi data pada GyTAR unggul sekitar 0,3620 ms lebih cepat dari rata-rata perolehan GPSR, dengan nilai masing-masing $2,2432 \mathrm{~ms}, 2,2857 \mathrm{~ms}$, dan 2,3538 ms.

End-to-end delay terjadi karena ketika jumlah komunikasi bertambah, node-node kendaraan lain sebagai perantara untuk mengirimkan layanan dari node sumber ke node tujuan cenderung semakin banyak yang terpakai sehingga paket-paket dari layanan harus melalui buffer, menyebabkan waktu pengiriman menjadi semakin lama. Terlebih, dalam skenario perkotaan, mekanisme lampu lalu lintas berdampak pada efek clustering, dimana sekumpulan kendaraan pada ruas persimpangan tertentu berkumpul untuk menunggu lampu berubah hijau menyebabkan tingginya kepadatan node dan delay yang diperlukan.

Berdasarkan keseluruhan perolehan end-to-end delay tersebut, GyTAR mengungguli GPSR secara konsisten pada skenario lingkungan perkotaan, membuktikan bahwa mekanisme routing berbasis persimpangan sangat cocok diaplikasikan dan dioptimasi pada lingkungan perkotaan yang memang terdapat banyak persimpangan.

GyTAR lebih adaptif pada lingkungan perkotaan mengingat pertimbangan keputusan routing-nya yang didasarkan pada kepadatan trafik yang memanfaatkan kondisi ramainya kendaraan di persimpangan sebagai alternatif forwarding node dan curve metric next hop yang lebih dekat dengan node tujuan. Pertimbangan ini dapat mengurangi kemungkinan terjadinya local optima, tidak seperti algoritma routing GPSR yang menerapkan greedy routing secara murni hanya mempertimbangkan posisi tetangga yang terdekat dengan tujuan. Terlebih, ketika mode recovery GPSR atau mode perimeter diterapkan pada kondisi local optima, dapat menyebabkan waktu yang dibutuhkan paket hingga mencapai tujuan menjadi lebih besar.

\subsubsection{Analisis Packet Delivery Ratio}

Dari data yang diperoleh pada Tabel 4, terlihat perbandingan rata-rata pengiriman sukses atau packet delivery ratio pada GyTAR di lingkungan perkotaan lebih baik dibandingkan performansi GPSR. Nilai packet delivery ratio protokol routing GyTAR stabil di kisaran 0,78 ke atas untuk semua jenis komunikasi. Adapun untuk komunikasi data dengan jumlah koneksi masing-masing 10, 20, dan 30, GyTAR memiliki perolehan PDR sebesar 0,9697, 0,9559, dan 0,9487 . Nilai ini unggul sekitar 0,010 dari rata-rata packet delivery ratio pada GPSR yang masingmasing komunikasinya memiliki nilai sebesar $0,9492,0,9475$, dan 0,9471 . 
Pada skenario perkotaan dengan mekanisme lampu lalu lintas ini, GPSR memperoleh nilai PDR yang lebih kecil dikarenakan penerapan perimeter mode sebagai strategi ketika local optima terjadisebagai contoh ketika forwarding node tersendat di persimpangan jalan dengan menunggu lampu sampai hijau untuk berjalan - membuat paket dikirim secara bertahap ke node-node tetangganya yang dekat justru memakan waktu lebih lama untuk sampai ke node tujuan.

Berbeda dengan GyTAR yang justru mengambil manfaat dari karakteristik lingkungan perkotaan sehingga mampu memberikan performansi kesuksesan pengiriman yang jauh lebih baik. Keberadaan persimpangan dan keberadaan lampu lalu lintas dimanfaatkan greedy traffic aware routing ini sebagai pertimbangan pemilihan. Semakin padat jumlah kendaraan yang ada di sebuah persimpangan, semakin kecil kemungkinan terjadinya void atau semakin banyak alternatif forwarding node.

Demikian ketika terjadi kondisi local optima, GyTAR akan menerapkan strategi carry and forward yakni paket akan dibawa node kendaraan terkini sampai lampu hijau atau mobil berjalan dan ia menemukan node tetangganya yang berada di persimpangan atau berada lebih dekat ke persimpangan selanjutnya. Secara berkebalikan, GPSR yang memilih next hop secara murni dengan pertimbangan jarak yang paling dekat dengan node tujuan justru dirugikan dengan kondisi terhenti pada lampu lalu lintas ini, sebab permilihan node diambil dari sekumpulan kendaraan yang statis dengan posisi relatif saling berdekatan, sehingga perpindahan paket antar node tipis selisih jaraknya.

Tabel 4. Packet Delivery Ratio GPSR dan GyTAR di Perkotaan

\begin{tabular}{|c|c|c|c|c|c|}
\hline \multirow{4}{*}{$\begin{array}{c}\text { Packet } \\
\text { Delivery }\end{array}$} & \multicolumn{2}{|c|}{ Komunikasi Node } & $\mathbf{1 0}$ & $\mathbf{2 0}$ & $\mathbf{3 0}$ \\
\cline { 2 - 6 } Ratio & \multirow{3}{*}{ GPSR } & Data & 0,9492 & 0,9475 & 0,9471 \\
\cline { 3 - 6 } & & Suara & 0,8236 & 0,7937 & 0,7684 \\
\cline { 3 - 6 } & \multirow{3}{*}{ GyTAR } & Video & 0,9488 & 0,9431 & 0,9326 \\
\cline { 3 - 6 } & & Data & 0,9697 & 0,9559 & 0,9487 \\
\cline { 3 - 6 } & & Suara & 0,8578 & 0,8223 & 0,7868 \\
\cline { 3 - 6 } & Video & 0,9543 & 0,9506 & 0,9372 \\
\hline
\end{tabular}

Tabel 5. Packet Loss GPSR dan GyTAR di Perkotaan

\begin{tabular}{|c|c|c|c|c|c|}
\hline \multirow{4}{*}{$\begin{array}{c}\text { Packet Loss } \\
(\%)\end{array}$} & \multirow{2}{*}{ Komunikasi Node } & $\mathbf{1 0}$ & $\mathbf{2 0}$ & $\mathbf{3 0}$ \\
\cline { 2 - 6 } & \multirow{3}{*}{ GPSR } & Data & 5,08 & 5,25 & 5,29 \\
\cline { 3 - 6 } & & Suara & 17,64 & 20,63 & 23,16 \\
\cline { 3 - 6 } & \multirow{3}{*}{ GyTAR } & Video & 5,12 & 5,69 & 6,74 \\
\cline { 3 - 6 } & & Data & 3,03 & 4,41 & 5,13 \\
\cline { 3 - 6 } & Suara & 14,22 & 17,77 & 21,32 \\
\cline { 3 - 6 } & Video & 4,57 & 4,94 & 6,28 \\
\hline
\end{tabular}

Tabel 6. NRO GPSR dan GyTAR di Perkotaan

\begin{tabular}{|c|c|c|c|c|c|}
\hline \multirow{4}{*}{ NRO } & \multicolumn{2}{|c|}{ Komunikasi Node } & $\mathbf{1 0}$ & $\mathbf{2 0}$ & $\mathbf{3 0}$ \\
\cline { 2 - 6 } & \multirow{3}{*}{ GPSR } & Data & 0,340 & 0,571 & 0,750 \\
\cline { 3 - 6 } & & Suara & 0,478 & 0,588 & 0,822 \\
\cline { 3 - 6 } & \multirow{3}{*}{ GyTAR } & Video & 1,005 & 1,010 & 1,019 \\
\cline { 3 - 6 } & & Data & 0,313 & 0,513 & 0,620 \\
\cline { 3 - 6 } & & Suara & 0,550 & 0,553 & 0,600 \\
\cline { 3 - 6 } & & Video & 1,004 & 1,005 & 1,007 \\
\hline
\end{tabular}

\subsubsection{Analisis Packet Loss}

Secara konsisten dari perolehan data end-to-end delay dan packet delivery ratio sebelumnya, Tabel 5 menunjukkan konsistensi keunggulan performansi protokol routing GyTAR dari parameter packet loss pada skenario lingkungan perkotaan. GyTAR mengungguli GPSR dalam besaran packet loss dengan nilai yang berkisar dari 3,03\% sampai $21,32 \%$, sementara GPSR lebih banyak mengalami packet loss dengan kisaran dari 5,08\% sampai $23,16 \%$.

Kedua algoritma greedy routing ini secara umum dipastikan memiliki probabilitas terjadinya packet loss setiap kali membangun hubungan komunikasi di antara node kendaraan dengan mobilitas yang sangat dinamis ini. Ketika algoritma greedy routing memilih next hop dengan pertimbangan jarak yang terdekat dari node tujuan, sebetulnya secara langsung juga membawa kepada masalah kemungkinan pemilihan node yang berada dalam ambang batas radius transmisi.

Adapun mekanisme pemilihan berdasarkan persimpangan terdekat yang diutamakan GyTAR menjadi alasan dasar lebih unggulnya performansi GyTAR dibandingkan GPSR. Hal ini karena mekanisme ini lebih adaptif dengan keadaan nyata di lingkungan perkotaan yang memang terdapat banyak persimpangan.

Masalah pada GyTAR yang membawa pada packet loss dapat terjadi pada kondisi ketika radius transmisi jauh lebih kecil dibandingkan jarak antara dua persimpangan yang berurutan. Walaupun demikian, sebenarnya sudah diperkecil dengan strategi recovery "carry and forward" - sebagaimana GPSR pun memiliki strategi recovery berupa mode perimeter setiap local optima tejadi.

\subsubsection{Analisis Normalized Routing Overhead}

Routing overhead pada protokol routing berbasis posisi ini berasal dari beacon atau pesan hello yang dikirim secara periodik untuk mengetahui posisi terkini dari node-node tetangga dalam radius transmisinya dan informasi yang ikut dikirim bersamaan dengan paket. GPSR menelan lebih banyak nilai normalized routing overhead ketika melakukan mekanisme recovery-nya, yaitu mode perimeter.

Pada mode ini, paket dikirim secara lebih sering atau bertahap dengan node-node yang berdekatan, menyebabkan pertukaran informasi yang terjadi pun menjadi semakin meningkat-berbeda dengan algoritma GyTAR yang melakukan strategi recoverynya dengan carry and forward di mana paket terus dibawa oleh kendaraan terkini sampai ia menemukan node kendaraan yang dinilai lebih tepat, jadi proses transfer paket pun akan lebih minim. Nilai NRO pada GPSR yang lebih besar dibandingkan dengan perolehan NRO pada GyTAR ini mengindikasikan bahwa performansi GyTAR dalam hal pembebanan 
trafik di jaringan masih lebih baik dibandingkan dengan GPSR, sebagaimana yang tertera pada Tabel 6.

\subsection{Analisis Skenario Lingkungan Jalan Tol}

\subsubsection{Analisis End-to-End Delay}

Sebagaimana tersaji pada Tabel 7, bahwa nilai end-to-end delay GyTAR lebih besar dibandingkan dengan end-to-end delay pada GPSR atau dengan kata lain, GPSR memberi performansi end-to-end delay yang lebih unggul dibandingkan GyTAR pada skenario lingkungan jalan tol.

Seperti dijelaskan sebelumnya, GPSR mengungguli GyTAR pada skenario jalan tol dengan nilai end-toend delay yang lebih kecil. Hal ini menunjukkan bahwa algoritma greedy routing murni (GPSR) memiliki performansi yang lebih adaptif pada jalan tol dibandingkan GyTAR. Alasannya tak lain karena karakteristik GyTAR yang berbasiskan persimpangan dan pertimbangan akan kepadatan trafik secara geografis tidak sesuai dengan karakteristik fisik jalan tol. Pada peta jalan tol Cipularang yang digunakan ini, kondisi jalan adalah lurus dan searah tanpa ada persimpangan sehingga GyTAR tidak mampu mengoptimalkan mekanisme routing-nya pada lingkungan seperti ini dan akan lebih sering melakukan mode recovery-nya.

Tabel 7. End-to-end Delay GPSR dan GyTAR di Jalan Tol

\begin{tabular}{|c|c|c|c|c|c|}
\hline \multirow{7}{*}{$\begin{array}{c}\text { End-to-End } \\
\text { Delay }\end{array}$} & \multicolumn{2}{|c|}{ Komunikasi Node } & 10 & 20 & 30 \\
\hline & \multirow{3}{*}{ GPSR } & Data & 2,5013 & 2,6977 & 2,7187 \\
\hline & & Suara & 1,9249 & 2,0072 & 2,6982 \\
\hline & & Video & 2,3600 & 2,7611 & 2,9076 \\
\hline & \multirow{3}{*}{ GyTAR } & Data & 3,0145 & 3,2000 & 3,2232 \\
\hline & & Suara & 1,9955 & 2,3412 & 2,7213 \\
\hline & & Video & 2,8342 & 3,3013 & 3,3218 \\
\hline
\end{tabular}

Tabel 8. Packet Delivery Ratio GPSR dan GyTAR di Jalan Tol

\begin{tabular}{|c|c|c|c|c|c|}
\hline \multirow{7}{*}{$\begin{array}{c}\text { Packet } \\
\text { Delivery } \\
\text { Ratio }\end{array}$} & \multicolumn{2}{|c|}{ Komunikasi Node } & 10 & 20 & 30 \\
\hline & \multirow{3}{*}{ GPSR } & Data & 0,9289 & 0,9211 & 0,9123 \\
\hline & & Suara & 0,8000 & 0,7845 & 0,7667 \\
\hline & & Video & 0,8727 & 0,8703 & 0,8647 \\
\hline & \multirow{3}{*}{ GyTAR } & Data & 0,9107 & 0,9036 & 0,8943 \\
\hline & & Suara & 0,7833 & 0,7743 & 0,7530 \\
\hline & & Video & 0,8611 & 0,8531 & 0,8520 \\
\hline
\end{tabular}

Tabel 9. Packet Loss GPSR dan GyTAR di Jalan Tol

\begin{tabular}{|c|c|c|c|c|c|}
\hline \multirow{4}{*}{$\begin{array}{c}\text { Packet Loss } \\
\text { (\%) }\end{array}$} & \multicolumn{2}{|c|}{ Komunikasi Node } & $\mathbf{1 0}$ & $\mathbf{2 0}$ & $\mathbf{3 0}$ \\
\cline { 2 - 6 } & \multirow{3}{*}{ GPSR } & Data & 7,11 & 7,89 & 8,77 \\
\cline { 3 - 6 } & & Suara & 20 & 21,55 & 23,33 \\
\cline { 3 - 6 } & & Video & 12,73 & 12,97 & 13,53 \\
\cline { 3 - 6 } & \multirow{3}{*}{ GyTAR } & Data & 8,93 & 9,64 & 10,57 \\
\cline { 3 - 6 } & & Suara & 21,67 & 22,57 & 24,7 \\
\cline { 3 - 6 } & Video & 13,89 & 14,69 & 14,8 \\
\hline
\end{tabular}

Tabel 10. NRO GPSR dan GyTAR di Jalan Tol

\begin{tabular}{|c|c|c|c|c|c|}
\hline \multirow{7}{*}{ NRO } & \multicolumn{2}{|c|}{ Komunikasi Node } & 10 & 20 & 30 \\
\hline & \multirow{3}{*}{ GPSR } & Data & 2,169 & 2,278 & 2,356 \\
\hline & & Suara & 1,562 & 1,557 & 1,562 \\
\hline & & Video & 1,508 & 1,533 & 1,620 \\
\hline & \multirow{3}{*}{ GyTAR } & Data & 1,701 & 1,732 & 1,744 \\
\hline & & Suara & 0,589 & 0,630 & 0,979 \\
\hline & & Video & 1,492 & 1,522 & 1,543 \\
\hline
\end{tabular}

Perolehan end-to-end delay kedua protokol routing pada lingkungan jalan tol ini bila dibandingkan dengan keseluruhan perolehan end-toend delay pada lingkungan perkotaan sebelumnya, memiliki nilai yang lebih tinggi atau lebih buruk. Hal ini karena walaupun pada lingkungan jalan tol tiap node kendaraan bergerak dengan kecepatan yang lebih tinggi-pada simulasi ini di-set dalam kisaran 60-10 km per jam-posisi mereka satu sama lain saling berjauhan sehingga entitas jaringan menjadi lengang dan kemungkinan neighboring table yang dimiliki sebuah node untuk berubah dalam waktu singkat (outdated) pun menjadi lebih besar, sehingga perlu menunggu forwarding node berikutnya untuk dapat mentransmit paket.

\subsubsection{Analisis Packet Delivery Ratio}

Sebagaimana tersaji pada Tabel 8, bahwa packet delivery ratio GPSR - masih secara konsisten dengan perolehan end-to-end delay-memberi nilai yang lebih baik dibandingkan dengan GyTAR.

Semakin bertambahnya jumlah komunikasi antar node, nilai packet delivery ratio semakin berkurang nilainya, baik pada GPSR maupun pada GyTAR. Hal ini dikarenakan kondisi jaringan di jalan tol yang relatif lengang menyebabkan terbatasnya utilitas node pada lingkungan ini. Kemungkinan neighboring node yang berada dalam radius transmisi dalam waktu singkat pun memperbesar kemungkinan outdated-nya neighbor table yang dimiliki sebuah node sehingga ketika paket dikirim, next hop dapat saja menghilang atau unreachable menyebabkan sebuah failure pada komunikasi-jika strategi recovery pun gagal diimplementasikan.

Perolehan rasio kesuksesan pengiriman pada lingkungan jalan tol ini secara keseluruhan lebih rendah dibandingkan PDR pada skenario perkotaan. Hal ini dipengaruhi oleh kondisi kelenggangan trafik yang menjadi faktor terhambatnya proses forwarding node karena proses penentuan next hop pada node tetangganya menjadi sangat terbatas pada kedua greedy routing ini, terlebih untuk metode routing GyTAR yang berbasis persimpangan.

Sesuai dengan perolehan data pada Tabel 9, yakni end-to-end delay dan packet delivery ratio, nilai packet loss protokol routing GPSR pun lebih kecil dibandingkan protokol routing GyTAR pada skenario lingkungan jalan tol.

\subsubsection{Analisis Packet Loss}

GPSR menangani kondisi local optima pada skenario jalan tol ini dengan mode perimeter, di mana algoritma ini akan terus berusaha mencari node-node yang berada di sekitarnya sebagai forwarding node hingga menemukan node yang jaraknya lebih dekat dengan tujuan. Mekanisme seperti ini lebih adaptif pada kondisi jalan tol yang arahnya dinamis karena paket difokuskan untuk terus diberikan pada node dengan posisi terdekat dengan tujuan. Berbeda 
dengan penanganan local optima pada GyTAR yang melakukan proses carry and forward. Proses demikian akan membuat paket lebih lama dibawa oleh sebuah forwarding node hingga akhirnya ditemukan node tetangga yang memenuhi pertimbangan kepadatan trafik, atau baru kemudian berdasarkan besar curvemetric ke tujuan dimana kemungkinan ditemukannya next hop dengan mekanisme ini kecil jika pada lingkungan lalu lintas jalan tol. Mekanisme yang demikian mempengaruhi performansi packet loss pada GPSR sehingga mengungguli GyTAR pada skenario lingkungan jalan tol.

\subsubsection{Analisis Normalized Routing Overhead}

Walaupun untuk metrik performansi sebelumnya berupa delay, packet delivery ratio, dan packet loss untuk lingkungan jalan tol diungguli oleh GPSR, namun besarnya routing overhead pada GPSR tetap lebih besar dibandingkan dengan GyTAR.

Berdasarkan perolehan data yang tersaji pada Tabel 10 bahwa Normalized Routing Overhead (NRO) GyTAR berkisar antara 0,589 hingga 1,744, sementara GPSR memiliki kisaran yang lebih tinggi yaitu dari 1,508 hingga 2,356.

Dibandingkan dengan skenario perkotaan, normalized routing overhead ini, baik pada GPSR ataupun GyTAR, memiliki nilai yang lebih besar dibandingkan dengan skenario lingkungan jalan tol ini. Hal ini dikarenakan kondisi jalan tol yang relatif lengang dan terbatas ketersediaan node-node kendaraan tetangga sebagai forwarding mode-nya menyebabkan kondisi local optimum lebih rentan terjadi. Ketika kondisi ini terjadi, paket akan berada dalam mode recovery dan terus mencari informasi terkini hingga forwarding node yang tepat sebagaimana mekanisme utamanya bekerja berhasil ditemukan.

Nilai NRO pada GPSR yang lebih besar dibandingkan dengan perolehan NRO pada GyTAR ini mengindikasikan bahwa performansi GyTAR dalam hal pembebanan trafik di jaringan pada lingkungan jalan tol masih lebih baik dibandingkan dengan GPSR.

\section{Kesimpulan}

Kesimpulan yang dapat diambil dari hasil penelitian dan analisis yang telah dilakukan adalah:

a. Greedy Traffic Aware Routing Protocol (GyTAR) memiliki performansi yang lebih baik pada skenario perkotaan dibandingkan GPSR dilihat dari seluruh parameter end-to-end delay, packet delivery ratio, packet loss, dan normalized routing overhead yang lebih baik dari GPSR dengan besar rata-rata nilai masing-masing untuk layanan data yakni $2,294 \mathrm{~ms}, 0,958,4,19 \%$, dan 0,482 ; untuk layanan suara sebesar $2,185 \mathrm{~ms}$, $0,8223,17,77 \%$, dan 0,567 ; serta untuk layanan video sebesar 2,432 ms, 0,947, 5,26\%, dan 1,005. Greedy Perimeter Stateless Routing (GPSR) memiliki metrik performansi yang lebih baik dibandingkan dengan GyTAR pada skenario jalan tol pada parameter end-to-end delay, packet delivery ratio, dan packet loss dengan besar ratarata nilai masing-masingnya untuk layanan data sebesar 2,639 ms, 0,920, dan 7,923\%; untuk layanan suara sebesar 2,2101 ms, 0,783, 21,62\%; serta untuk layanan video sebesar $2,6762 \mathrm{~ms}$, $0,869,13,07 \%$.

b. Nilai normalized routing overhead (NRO) pada kedua skenario lingkungan diungguli oleh GyTAR dengan perolehan rata-rata di masingmasing lingkungan perkotaan dan jalan tol sebesar 0,685 dan 1,326.

c. Bertambahnya jumlah komunikasi yang dibangun sebanding dengan degradasi kualitas atau performansi masing-masing protokol routing.

\section{Daftar Pustaka}

[1] Braga, R. B. dan Hervé Martin, "Understanding Geographic Routing in Vehicular Ad Hoc Networks", The Third International Conference on Advanced Geographic Information Systems, Applications, and Services, 2011.

[2] Gadkari, Mushtak Y. dan Nitin B. Sambre. 2011, "VANET: Routing Protocols, Security Issues and Simulation Tools", IOSR Journal of Computer Engineering (IOSRJCE), ISSN: 2278-0661, Volume 3, Issue 3, PP 28-38 JulyAgustus 2012.

[3] Jerbi, Moez, Rabah Meraihi, Sidi-Mohammed Senouci, dan Yacine Ghamri-Doudane, "Traffic Aware Geographic Routing Protocol for Vehicular Networks in City Environments", France: Networks and Multimedia Systems Research Group, 2006.

[4] Jerbi, Moez, Rabah Meraihi, Sidi-Mohammed Senouci, dan Yacine Ghamri-Doudane, "GyTAR: Improved Greedy Traffic Aware Routing Protocol for Vehicular Ad Hoc Networks in City Environments", VANET '06: Proceedings of the 3rd International Workshop on Vehicular Ad Hoc Networks, New York, 2006.

[5] Munera, J., J. M. de Fuentes, A. I. GonzálezTablas, "Towards a Comparable Evaluation for VANET Protocols: NS-2 Experiments Builder Assistant and Extensible Test Bed", Computer Science Dept. University Carlos III of Madrid, Spain, 2011.

[6] Mustafa, Bilal dan Umar Waqas Raja, "Issues of Routing in VANET", Master Thesis, Swedia: Blekinge Institute of Technology, Juni 2010.

[7] Raw, Ram Shringar dan Sanjoy Das, "Performance Comparison of Position-Based Routing Protocols in Vehicle-to-Vehicle (V2V) Communication", International Journal of 
Engineering Science and Technology (IJEST), New Delhi: Jawaharlal Nehru University, 2011.

[8] Schnaufer, Sascha, Holger Füßler, Matthias Transier, dan Wolfgang Effelsberg, "Unicast Ad-Hoc Routing in Vehicular City Scenarios", Germany: University of Mannheim, 2007.

[9] Singh, Pranav Kumar dan Kapang Lego, "Towards the Analysis of Adhoc Routing Protocol in VANET Environment", Int. J. Open Problems Compt. Math., Vol. 3, No. 5, India, Desember 2010.

[10] Watfa, Mohammed, "Advances in Vehicular Ad-Hoc Networks: Development and Challenges", Master Thesis, University of Wollongong, UAE, Information Science Reference (an imprint of IGI Global), Hershey New York, 2010.

[11] Zeadally, Sherali, Ray Hunt, Yuh-Shyan Chen, Angela Irwin, dan Aamir Hassan, "Vehicular Ad Hoc Networks (VANETS): Status, Results, and Challenges", USA: Springer Science+Business Media, LLC, 2010. 